\title{
Development and testing of an online method to measure ambient fine particulate reactive oxygen species (ROS) based on the $2^{\prime}, 7^{\prime}$-dichlorofluorescin (DCFH) assay
}

\author{
L. E. King and R. J. Weber \\ School of Earth and Atmospheric Sciences, Georgia Institute of Technology, Atlanta, GA, USA \\ Correspondence to: R. J. Weber (rweber@eas.gatech.edu)
}

Received: 17 February 2013 - Published in Atmos. Meas. Tech. Discuss.: 4 April 2013

Revised: 7 June 2013 - Accepted: 11 June 2013 - Published: 11 July 2013

\begin{abstract}
An online, semi-continuous instrument to measure fine particle $\left(\mathrm{PM}_{2.5}\right)$ reactive oxygen species (ROS) was developed based on the fluorescent probe $2^{\prime} 7^{\prime}$ dichlorofluorescin (DCFH). Parameters that influence probe response were first characterized to develop an optimal method for use in a field instrument. The online method used a mist chamber scrubber to collect total (gas plus particle) ROS components $\left(\operatorname{ROS}_{t}\right)$ alternating with gas phase ROS $\left(R S_{g}\right)$ by means of an inline filter. Particle phase ROS $\left(\operatorname{ROS}_{\mathrm{p}}\right)$ was determined by the difference between $\mathrm{ROS}_{\mathrm{t}}$ and ROS $\mathrm{g}$. The instrument was deployed in urban Atlanta, Georgia, USA, and at a rural site during various seasons. Concentrations from the online instrument generally agreed well with those from an intensive filter measurement of $\mathrm{ROS}_{\mathrm{p}}$. Concentrations of the ROS $\mathrm{p}$ measurements made with this instrument were lower than reported in other studies, often below the instrument's average limit of detection $\left(0.15 \mathrm{nmol} \mathrm{H}_{2} \mathrm{O}_{2}\right.$ equivalents $\left.\mathrm{m}^{-3}\right)$. Mean $\mathrm{ROS}_{\mathrm{p}}$ concentrations were $0.26 \mathrm{nmol} \mathrm{H}_{2} \mathrm{O}_{2}$ equivalents $\mathrm{m}^{-3}$ at the Atlanta urban sites compared to $0.14 \mathrm{nmol} \mathrm{H}_{2} \mathrm{O}_{2}$ equivalents $\mathrm{m}^{-3}$ at the rural site.
\end{abstract}

\section{Introduction}

Reactive oxygen species (ROS) when introduced into a biological system have a strong tendency to disrupt the electrochemical balance. The amount of disruption depends on factors such as the amount of ROS introduced or produced within the system, the location of the introduction or production of the reactive species, the duration of the insult and a host of other factors, many of which have yet to be ascertained in nature as well as in scope (Barrett et al., 1999; Morgan et al., 2001; Oberdörster, 2004; Rothe and Valet, 1990; Squadrito et al., 2001; Sugamura and Keaney, 2011; Xia et al., 2006). Human exposure to ROS can occur by a number of known routes. ROS associated with gaseous or particulate pollutants generated in the atmosphere may be transported into the respiratory system. Their deposition generates adverse effects within cells of that location. Compounds associated with aerosol particles may also be deposited and result in either a direct or indirect generation of ROS intracellularly, in which the oxidative stress may not be limited to the immediate area of deposition.

Reactive and oxidizing species have been shown to be detrimental to biological systems in a wide variety of ways, including disrupting protein pathways, increasing the breakdown of key cellular structures and leading to the eventual death of individual cells, prior to which large amounts of cellular stress translate into wider systemic stress in organisms (Antonini et al., 1998; Barrett et al., 1999; Squadrito et al., 2001; Sugamura and Keaney, 2011). Atmospheric exposure to ROS can occur either in the gas or particle phase. Gas phase ROS $\left(\operatorname{ROS}_{\mathrm{g}}\right)$ is most likely to be removed in the upper mucus membranes (Kao and Wang, 2002), whereas other studies (Pope et al., 1995) have demonstrated the ability of fine particles, which would include particle phase ROS $\left(\operatorname{ROS}_{\mathrm{p}}\right)$, to penetrate further into the lungs and deposit in the alveoli.

Atmospheric studies to measure ambient ROS have generally focused on gas phase measurements (Reeves and Penkett, 2003; Klippel et al., 2011), typically using 
fluorescent probes. $\operatorname{ROS}_{\mathrm{p}}$ measurements have primarily been made using filters for particle collection and analysis of extracts using similar probes (Hung and Wang, 2001; Venkatachari et al., 2005, 2007). These fluorescent probes, such as 2', 7'-dichlorofluorescin (DCFH) (Hung and Wang, 2001), Amplex Red (Votyakova and Reynolds, 2004), phydroxyphenylacetic acid (POHPAA) (Lee et al., 1991) and others, have been adapted from their use in intracellular ROS measurements for direct measurements in the atmosphere. Various ROS will oxidize these probes, which then fluoresce at specific wavelengths when excited. Fluorescent probes are most often chosen for their fast response rates, linear response to varying ROS concentrations and either dedicated response to a particular compound (e.g., Amplex Red) (Zhou et al., 1997) or lack of chemical specificity (e.g., DCFH; LeBel et al., 1992).

The overall findings of measurements of ambient ROS have shown some associations with other atmospheric species. $\operatorname{ROS}_{\mathrm{p}}$ is positively correlated with both Fe concentration and other transition metals (See et al., 2007), and a positive correlation with organic concentrations (Wang et al., 2010) has been observed. Some correlations between ROS and ozone have been reported, particularly in the early to mid-afternoon (Venkatachari et al., 2005).

A potential drawback to previously reported $\mathrm{ROS}_{\mathrm{p}}$ concentrations is that previous studies may be susceptible to sampling artifacts. Filter-based studies, particularly for reactive compounds, are likely limited by long sample collection times that may result in under-prediction of concentrations (Hung and Wang, 2001). Previous ROS $_{p}$ filter studies have also been challenging due to reported high and variable blank concentrations (Hung and Wang, 2001; Venkatachari et al., 2005, 2007).

Some preliminary results exist for an online method to measure $\operatorname{ROS}_{\mathrm{p}}$ (Venkatachari and Hopke, 2008; Wang et al., 2011). This instrument couples the particle-into-liquid sampler (PILS) with a flow system that mixes DCFH and a catalyst, peroxidase from horseradish (HRP) with the PILS sample stream-contained soluble $\mathrm{PM}_{2.5}$ components (Venkatachari and Hopke, 2008). After utilizing mixing elements to combine and sufficiently react the sample ROS with the fluorescent reagents, the sample is measured using a spectrometer. Results from a summertime week-long field operation in Rochester, NY (Wang et al., 2011), showed an average of $8.3 \pm 2.2 \mathrm{nmol}_{2} \mathrm{O}_{2}$ equivalents $\mathrm{m}^{-3}$. This study also indicated a diurnal trend in $\mathrm{ROS}_{\mathrm{p}}$ with an increase in daytime concentrations, as well as higher values on weekdays than on weekends. These reported values exceeded ambient values found on filters in previous studies in the USA and Taiwan (Hung and Wang, 2001; Venkatachari et al., 2005, 2007). These results appear to indicate that $\operatorname{ROS}_{p}$ loss from ambient filters can be minimized by using a continuous online system with virtually no delay between collection and analysis.

\section{Materials and methods}

\subsection{Primary materials}

For this study the DCFH probe was chosen to provide a comprehensive ROS detector. Of the ROS probes commercially available, DCFH has a long and well-documented record of sensitivity in both cellular and atmospheric aerosol applications (Hung and Wang, 2001; Liu et al., 2007; Venkatachari and Hopke, 2008; Venkatachari et al., 2005, 2007; Wang et al., 2011; Black and Brandt, 1974; Cathcart et al., 1983; LeBel et al., 1992). 2', 7'-dichlorodihydrofluorescin diacetate (DCFHDA) was purchased from both Sigma Aldrich (St. Louis, MO, USA) and Calbiochem (EMD Chemicals, Billerica, MA, USA) depending on availability. Horseradish peroxidase (HRP) (Type II) was purchased exclusively from Sigma Aldrich. Hydrogen peroxide $(30 \%$, w/w) was purchased from J.T. Baker through VWR (Atlanta, GA, USA).

Primary analytical equipment included a spectrofluorometer (Maya2000Pro, Ocean Optics, Dunedin, FL, USA) with cutoff and long-pass filters for wavelengths greater than $515 \mathrm{~nm}$ and a $200 \mu \mathrm{m}$ slit. The spectrometer was further equipped with a flow-through cell of $450 \mu \mathrm{L}$ volume with a light path of $10 \times 4 \mathrm{~mm}$ (FIA-SMA-FL-ULT). The initial excitation source was a blue $(475 \mathrm{~nm})$ LED source manufactured by Mikropack (Ocean Optics, LS-475), replaced with a Jasco-manufactured $470 \mathrm{~nm}$ wavelength LED with adjustable voltage (LLS-470, Ocean Optics) to accommodate LED intensity loss with bulb age. Fiberoptic cables (SMA905, Ocean Optics) completed the primary analytical apparatus.

Solutions were pumped through the flow-through cell using an 8-channel peristaltic pump (Ismatec, Opfikon, Switzerland). Any tubing, glassware or other vessels for working solution storage or transport were shielded in aluminum foil to prevent photooxidation.

\subsection{Reagent preparation}

According to previously published methods (Cohn et al., 2008; LeBel et al., 1992), DCFHDA was dissolved in HPLCgrade ethanol in a portable darkroom (Silver Edition HydroHut, Flora Hydroponics, Atlanta, GA, USA), and either used immediately or stored in the freezer in an amber bottle, sealed to prevent evaporation of the solvent. To prepare the working solution of a desired concentration of DCFH, $0.01 \mathrm{~N} \mathrm{NaOH}$ was added to the DCFHDA solution to remove the acetate. After $30 \mathrm{~min}$, the solution was buffered with a sodium phosphate buffer ( $\mathrm{pH}$ 7.4) to halt the reaction, dilute the DCFH concentration, bringing the overall $\mathrm{pH}$ to 7.2 (allowable range, 7.2-7.4). $\mathrm{pH}$ was verified with a handheld pH monitor (VWR). A quantity of HRP (Type II, Sigma Aldrich) was then added to the solution to bring it to 0.51 units $\mathrm{HRP} \mathrm{mL}^{-1}$ solution, based on the specific purpogallin units per milligram for each lot of HRP. The working solution 
(DCFH + HRP) was then stored in an amber vessel or foilwrapped flask in the laboratory refrigerator at $2{ }^{\circ} \mathrm{C}$ and discarded after a period of 2 days. The original standard working solution was $5 \mu \mathrm{M}$ DCFH with 0.5 units $\mathrm{HRP} \mathrm{mL}^{-1}$ solution.

\section{Offline system for calibration and sensitivity analysis of DCFH}

\subsection{Initial method and analysis}

Initial evaluation of DCFH was conducted following the method described by Hung and Wang (2001) in which the probe was used to quantify the ROS concentrations from ambient particle filter extracts. A total of $3 \mathrm{~mL}$ of DCFHHRP solution were pipetted in the darkroom into $15 \mathrm{~mL}$ amber centrifuge vials, which were then covered with predrilled caps (1/16" diameter) and sealed with paper laboratory tape. These preloaded vials were stored in the refrigerator until use.

For analysis, the tape was briefly removed from the vials, and $0.1 \mathrm{~mL}$ of either deionized water (dI) or a hydrogen peroxide standard was pipetted through the cap hole. The tape was replaced and the vial briefly inverted to ensure that no peroxide remained uncombined with the DCFH solution. The vials were incubated in a $37^{\circ} \mathrm{C}$ water bath for $15 \mathrm{~min}$. The solution was then briefly agitated by hand and placed in line with the analytical system, shown in Fig. 1. A peristaltic pump moved the DCFH-HRP- $\mathrm{H}_{2} \mathrm{O}_{2}$ solution at $0.4 \mathrm{~mL} \mathrm{~min}^{-1}$ through the flow-through cell, while a selector valve directed $\mathrm{dI}$ through the cell when not measuring DCFH intensity. A small glass debubbler was also employed to reduce the signal interference by small air bubbles that may be introduced into the system, also run from the peristaltic pump. Volume loss from the discarded flow was approximately $10 \%$ of the overall sample flow. Sufficient dI was allowed to move through the system to return the fluorescent signal to a baseline value before analyzing the next sample. The entire system was plumbed with green PEEK tubing (1/16" outer diameter, $0.030^{\prime \prime}$ inner diameter, Upchurch Scientific, Oak Harbor, WA, USA).

As the solution moved through the flow cell, it was excited by the $475 \mathrm{~nm}$ light source, causing the $\mathrm{DCF}^{*}$ product to fluoresce at $530 \mathrm{~nm}$. This light intensity is transmitted via the fiber optic cable to the spectrophotometer. Fluorescent intensity at $530 \mathrm{~nm}$ was measured using SpectraSuite from Ocean Optics and recorded with an integration time of $500 \mathrm{~ms}$ and average of 10 scans. Prior to any analysis a dark spectrum signal was measured while blocking all light to the spectrometer and subtracted automatically from the light spectrum. Intensity values reported are average intensities of measurements made once the fluorescent signal was stabilized, after a minimum of $10 \mathrm{~min}$ from powering on the excitation source. Deionized water also provided a measurable signal

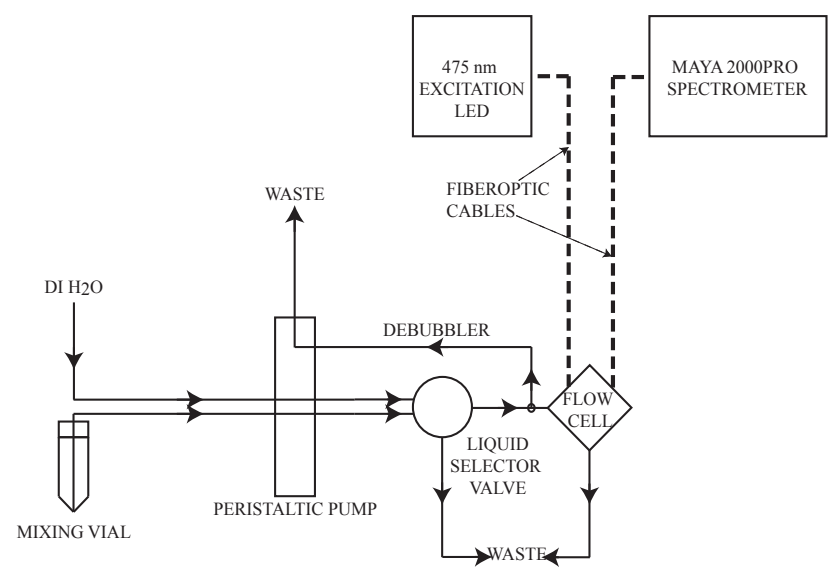

Fig. 1. Schematic for offline ROS analysis of standards and reagents combined in a mixing vial. DCFH $+\mathrm{ROS}\left(\mathrm{H}_{2} \mathrm{O}_{2}\right.$ for calibrations $)$ is pumped via the peristaltic pump through the flow cell, in which the concentration of DCF is measured at $530 \mathrm{~nm}$ by the spectrometer. A selector valve switches between sample and deionized water to provide a baseline and to clear out the flow cell between samples.

at $530 \mathrm{~nm}$, which was used as a surrogate for light source intensity and system flow stability over time.

An example of an initial calibration made with $\mathrm{H}_{2} \mathrm{O}_{2}$ solution concentrations of $100-400 \mathrm{nM}$ is shown in Fig. 2. This sample range was chosen as a representative span for the concentrations reported in $\mathrm{ROS}_{\mathrm{p}}$ analysis for typical filter measurement setups (Hung and Wang, 2001; Venkatachari et al., 2005, 2007).

\subsection{Offline sensitivity analysis}

Previous work has reported the need to control the DCFHHRP working solution storage temperature, storage time (solution age), $\mathrm{pH}$, and operational parameters including reaction temperature, $\mathrm{pH}$ and reaction time to achieve maximum reaction of DCFH with hydrogen peroxide. Parameters were optimized to reduce auto-oxidation and thus lengthen the usable lifespan of the DCFH-HRP solution, hereafter referred to as working solution (Cathcart et al., 1983; Black and Brandt, 1974), and to provide the greatest method response. Parameters were assessed primarily by comparing hydrogen peroxide calibration slopes relative to the base case, previously described. DCFH age was examined by comparing the calibration slope of a fresh solution with the calibration slope hours and days later. Reaction temperature was assessed by comparing calibration slopes of solutions incubated at varying temperatures from ambient $\left(23^{\circ} \mathrm{C}\right)$ to $65^{\circ} \mathrm{C}$ prior to analysis. A similar method of assessment was used to determine the optimal DCFH concentration and DCFH : sample volumetric ratios (e.g., the ratio of the volume of working solution to the volume of calibration standard). A $30: 1$ ratio, used for the base case, was not considered practical for a future online system. Finally, reaction time was assessed using 


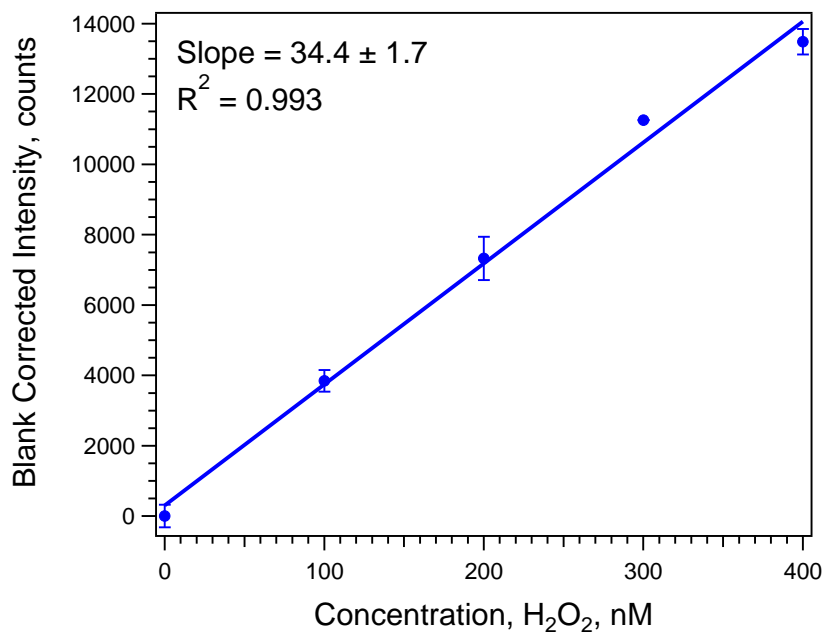

Fig. 2. Calibration of offline ROS assay using DCFH with known concentrations of $\mathrm{H}_{2} \mathrm{O}_{2}$. Error bars represent the standard deviation of multiple measurements $(n=5)$.

a different setup in order to measure reaction progress. In those tests, $0.1 \mathrm{~mL}$ of a hydrogen peroxide standard or $\mathrm{dI}$ was pipetted into the mixing vials as described previously with $3 \mathrm{~mL}$ of DCFH solution, briefly inverted to ensure that all liquids were combined and immediately placed in line with the detector. The sample line from vial to detector was shortened as much as possible to reduce delay time from which DCFH and peroxide were combined to initial detection of fluorescence, using the same $0.030^{\prime \prime}$ ID PEEK tubing as in the standard flow analysis setup from Fig. 1. The residence time in line prior to detection was $30 \mathrm{~s}$. The findings from these offline assessments are summarized in Table 1 and used in the application of the online instrument.

\section{Online instrument development}

\subsection{Mist chamber}

Originally known as the Cofer scrubber, mist chambers were developed to collect water soluble gases and particles for online analysis (Cofer III et al., 1985, 1986; Anderson et al., 2008; Spaulding et al., 2002). Mist chambers are generally a cylindrical glass structure with an air sample inlet at the bottom, a port on the side for introduction and removal of scrubbing liquids, and a nebulizing nozzle, as shown in Fig. 3. Sample air enters the chamber through the bottom nozzle. Inside the chamber, a capillary runs from just above the base and alongside the air nozzle for some vertical distance. Some minimum volume of liquid, usually water, is placed inside the mist chamber via the injection port. Venturi forces created by the airflow accelerate through the nozzle, draw liquid from the reservoir into the airstream and create a fine mist. Affixed to the top of the mist chamber is a

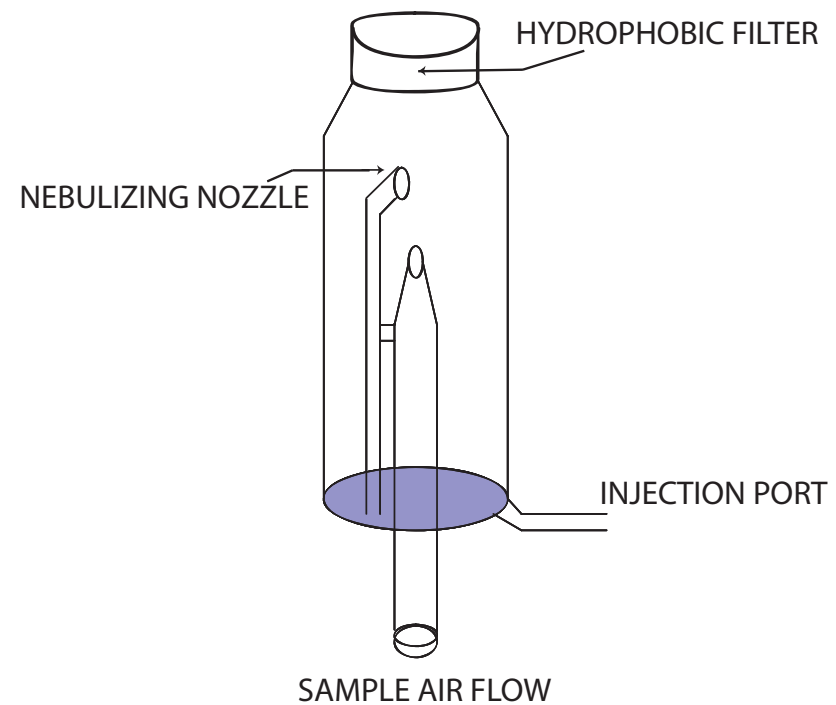

Fig. 3. Schematic of a mist chamber. Liquid is injected and extracted via the port at the bottom of the chamber. Sample air is drawn through the opening in the base of the chamber, nebulizing the liquid inside and creating a mist of droplets. Liquids are retained by means of a hydrophobic filter attached to the top of the mist chamber, which also refluxes liquid back down the sides of the glass.

Table 1. Optimal parameters for use in online instrumentation.

\begin{tabular}{ll}
\hline Parameter & Value \\
\hline Maximum viable DCFH useful age & 2 days \\
Reaction temperature & ambient \\
DCFH concentration & $10 \mu \mathrm{M}$ \\
Volumetric ratio & Arbitrary $(9: 1-30: 1)$ \\
Minimum reaction time & 3 min \\
\hline
\end{tabular}

filter pack (University Research Glassware (URG), Carrboro, NC, USA) equipped with a $1.0 \mu \mathrm{m}$ pore size hydrophobic filter (TefSep, Pall Corporation). This filter prevents the liquid from exiting the chamber, which refluxes down from the top of the mist chamber back to the reservoir. This liquid scrubs the soluble gases and particles from the airstream as it is continually recycled through the chamber. Some liquid is inevitably lost as water vapor in the exhaust flow. When sample airflow is halted, the liquid and its components in solution are withdrawn from the chamber for analysis. Analysis of the sample can occur while the next mist chamber sampling cycle starts.

Benefits of the mist chamber include operation without heating the sample and the ability to vary integration time in order to concentrate samples. The mist chamber has been shown to effectively collect compounds with a Henry's law constant, $K_{\mathrm{H}}$, of over $10^{3} \mathrm{M} \mathrm{atm}^{-1}$ (Spaulding et al., 2002). The potential drawbacks of the system include the need for a batch operation process, which tends to consume 


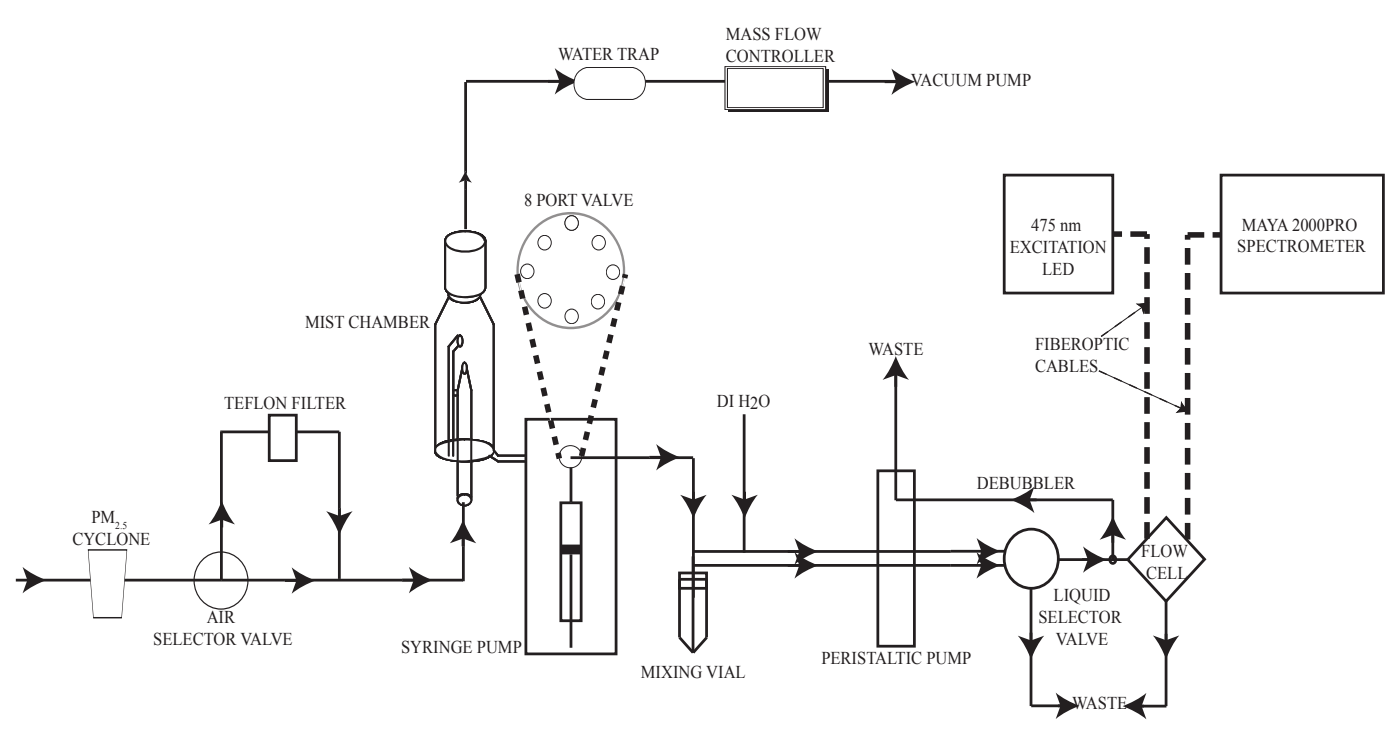

Fig. 4. Schematic of online $\mathrm{PM}_{2.5}$ ROS measurement approach using a mist chamber particle collection system and fluorometric probe.

more water as opposed to a continuous monitoring system. Mist chambers are also effective scrubbers of gases, unlike condensation-based systems, indicating the need for an effective gas phase control to effectively measure solely particle concentrations. A mist chamber was chosen as the particle collection for the online $\operatorname{ROS}_{\mathrm{p}}$ instrument in part due to control of sample integration times to overcome analytical detection limits.

\subsection{Online method setup}

The overall setup of the mist chamber-based ROS instrument is shown in Fig. 4. Ambient air is drawn through a cyclone $\left(\mathrm{PM}_{2.5}, 16.7 \mathrm{~L} \mathrm{~min}^{-1}\right.$, URG) and a copper inlet line. The airflow enters an automated valve that either directs it through a $47 \mathrm{~mm}$ filter pack (URG) containing a $2.0 \mu \mathrm{m}$ Teflon filter (Zefluor, Pall Corporation) for measurements of $\mathrm{ROS}_{\mathrm{g}}$, or bypasses the filter for a measurement of $\mathrm{ROS}_{\mathrm{g}}+\mathrm{ROS}_{\mathrm{p}}$, or total ROS $\left(\operatorname{ROS}_{t}\right)$. The sample air then enters the mist chamber, after which the scrubbed airstream exits through the hydrophobic filter. The airflow finally passes through a water trap followed by a mass flow controller (GFC-47, Aalborg), set nominally at $20 \mathrm{~L} \mathrm{~min}^{-1}$, and then to a vacuum pump (carbon vane, Gast $1 / 4 \mathrm{hp}$ ). These sampling system components were specifically chosen to maximize retention of $\mathrm{PM}_{2.5}$ and thus $\mathrm{ROS}_{\mathrm{p}}$.

A syringe pump equipped with an 8-port valve (V6 pump with $48 \mathrm{~K}$ resolution, Norgren Kloehn, Las Vegas, NV, USA) and a continuously operating peristaltic pump (4-channel, Ismatec) control the liquid portion of the instrument. One port of the syringe pump is connected to the mist chamber liquid inlet; the other ports led to a reservoir of the DCFH-HRP working solution, dI, waste, and a $15 \mathrm{~mL}$ amber centrifuge tube (mixing vial) as described in the offline analysis method.
The remaining three ports can be used for up to two hydrogen peroxide standards for automatic calibrations, and for an open port for introduction of air, as required. The V6 pump also electronically controls the power to the vacuum pump through a solid-state relay as well as the position of the sample air selector valve and a two-position liquid selector valve to change the source of the liquid flow into the flow cell.

The peristaltic pump continuously moves liquid from either the mixing vial or the $\mathrm{dI}$ reservoir through the flow cell. This amber mixing vial contains two PEEK tubing lines inserted through the hole in the cap. The line from the peristaltic pump extended to the vial bottom while the line from the syringe pump valve extended only a short distance past the cap. This setup allows for all liquid to be withdrawn completely via the longest line from the mixing vial, while the shorter line does not reach the liquid level within the vial at any time. A third channel on the peristaltic pump also controls flow from a glass debubbler in line just prior to the flowthrough cell. The fourth channel drains liquid from the water trap to protect the mass flow controller. The syringe and all other clear portions of this system are shielded from light with aluminum foil to inhibit photooxidation of the DCFH.

\subsection{Sampling automation and analysis}

The following describes a typical sample collection and analysis cycle using a looping routine in the syringe pump (Kloehn Control) software. The start of the sampling cycle begins with the syringe pump injecting $10 \mathrm{~mL}$ of $\mathrm{dI}$ into the mist chamber. The vacuum pump is started for a period of 5 min to collect soluble ROS ambient species in the mist chamber collection liquid. The vacuum pump is shut off, and the syringe pump withdraws $1.5 \mathrm{~mL}$ of the ROS-laden solution from the mist chamber; $0.5 \mathrm{~mL}$ of this from the top of the 
syringe is immediately discarded to remove any air from the liquid system. A total of $9 \mathrm{~mL}$ of working solution are then added to the syringe. The combined total $10 \mathrm{~mL}$ of sample liquid and working solution is forced into the mixing vial via the higher level tube. This process mixes the sample of dissolved ROS components and working solution. During this time, the peristaltic pump is running continually, pumping dI through the flow cell and the mixed sample-reagent solution from the vial is sent to waste, until after $1 \mathrm{~min}$, at which point the vial liquid has reached the selector valve, which then is actuated to direct vial liquid to the flow cell (dI now to waste). The reacted sample solution moves through the flow cell for $2.5 \mathrm{~min}$, at the end of which the fluorescent signal is recorded. This results in a fluorescent signal quantified after $4.5 \mathrm{~min}$ of reaction time. Deionized water in between samples provides a baseline as previously discussed.

During the analysis of the ambient sample by the spectrometer, the syringe pump cleans the mist chamber prior to reloading it for another sample by draining and discarding the remaining sample liquid. Water used for sample collection is added to the mist chamber. The air selector valve is adjusted to filter ambient air and the vacuum pump runs for $30 \mathrm{~s}$, rinsing the mist chamber with particle-free air and water (but does contain ambient $\mathrm{ROS}_{\mathrm{g}}$ ). The vacuum pump is shut off, and this water withdrawn and discarded.

After the final measurements of the fluorescent signal, the liquid selector valve returns to its prior state, pumping any remaining sample from the mixing vial to waste and rinsing the flow cell with dI. The syringe pump then also withdraws and discards remaining sample solution to completely empty the vial and flushes the vial once with dI.

Since part of the analysis time includes preparing the mist chamber for the next measurement, there is a delay of $5.5 \mathrm{~min}$ between sampling cycles. For example, one complete cycle of the general ROS sampling and analysis cycle takes 10.5 min when collecting sample in the mist chamber for $5 \mathrm{~min}$. Longer duty cycles were employed when the mist chamber sample collection time was increased to produce more concentrated samples.

\subsection{Mist chamber particle collection efficiency and liquid loss}

The mist chamber was constructed by the department glass blower, so variation between different chambers is possible. This variation and the subsequent potential operational collection efficiency differences must be evaluated. Collection efficiencies were determined by comparing the collection of sulfate with a simultaneous operation of the PILS-IC system (Orsini et al., 2003). The ROS instrument was operated entirely in $\mathrm{ROS}_{\mathrm{t}}$ mode and fitted with a gas denuder upstream. The collected liquid was drawn from the mist chamber into a vial, which was then analyzed manually by the same IC measuring the sample collected by the PILS. Multiple measurements of ambient $\mathrm{PM}_{2.5}$ sulfate concentrations

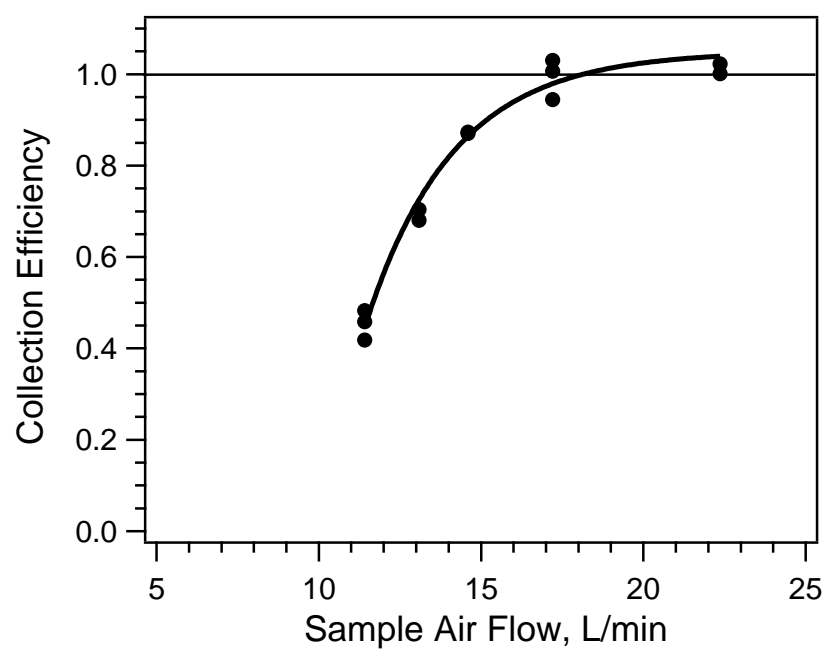

Fig. 5. Mist chamber collection efficiency. Collection efficiency determined by ratio of ambient sulfate measured with the mist chamber-IC to that from a PILS-IC system.

were conducted at different mist chamber sample airflow rates. The resulting collection efficiency (mist chamber sulfate to PILS sulfate) shown in Fig. 5 shows that this specific mist chamber should be operated at a minimum flow rate of $15 \mathrm{~L} \mathrm{~min}^{-1}$. Maximum flow rates for this particular setup were limited to approximately $25 \mathrm{~L} \mathrm{~min}^{-1}$ due to pressure drop across various elements of the system, mainly from the wetted hydrophobic refluxing filter.

While the refluxing hydrophobic filter that retains liquid in the mist chamber is effective, inevitably some liquid loss occurs. The final volume of liquid retained by the mist chamber is measured periodically to account for this loss to account and to determine the ambient concentration. This potential loss was also a motivating factor in the short sampling periods employed during the majority of the instrument's field deployment.

\subsection{Online calibration and dynamic liquid blanks}

The ROS instrument is calibrated with the mist chamber offline in an automated process using the analytical system just described. Instead of liquid from the mist chamber being combined with the DCFH working solution in the mixing vial, the same volume of a standard is used. This allows the verification of known concentrations as part of routine operation. "Blank", or auto-oxidation, measurements to adjust for working solution age and subsequent increase in baseline fluorescent intensity were also made using dI. Figure 6 shows a typical plot from such a calibration, using standard concentrations in the range anticipated for ambient sampling with the online instrument.

As "blank" measurements in this system are truly measurements of the auto-oxidation state of the working solution, they must be measured regularly during the sampling 


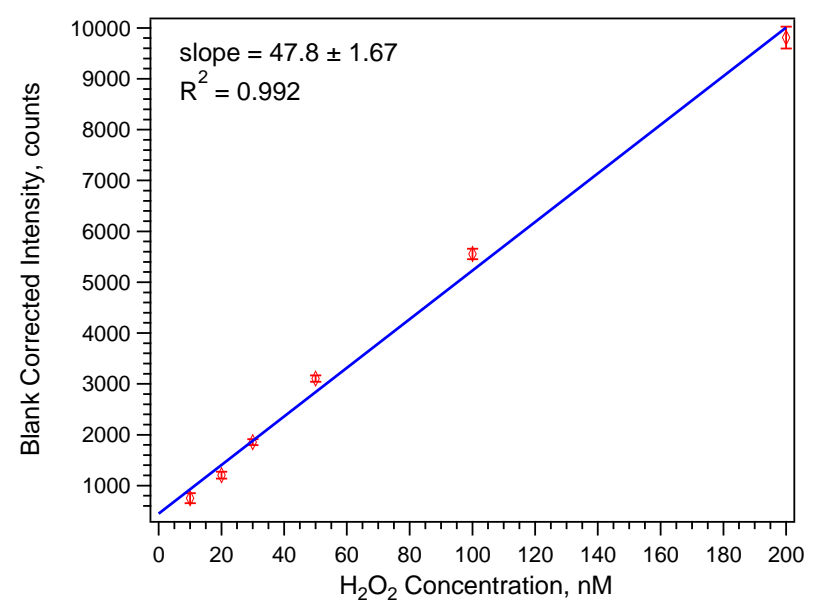

Fig. 6. Calibration of online ROS assay using DCFH with known concentrations of $\mathrm{H}_{2} \mathrm{O}_{2}$. Error bars represent the standard deviation of multiple measurements $(n=5)$.

operation to allow for dynamic correction of the sample fluorescent signal over time. The blank signal is measured after every 6 ambient measurements, or approximately every hour. Figure 7 shows a sample of the drift over roughly a $48 \mathrm{~h}$ sample period of the blank signal during field-testing of the instrument.

\subsection{Calculation of ambient ROS concentration}

The ROS concentration in the ambient air in $\mathrm{H}_{2} \mathrm{O}_{2}$ equivalents is calculated by

$C_{a}=\left(\frac{I-b}{a}\right)\left(\frac{V_{\mathrm{s}}}{1000 Q_{\mathrm{a}} t}\right) \quad 1000 \mathrm{~L} \mathrm{~m}^{-3}$,

where $I$ is the intensity of the fluorescent signal (counts), $b$ the intercept from calibration linear fit, $a$ the slope from calibration linear fit, $V_{\mathrm{s}}$ final solution volume $(\mathrm{mL})$ in mist chamber, and $Q_{\mathrm{a}}$ the average airflow through the mist chamber $\left(\mathrm{L} \mathrm{min}^{-1}\right.$, ambient $T$ and $p$ ) for a sampling period of $t$ (min). Multiplying $C_{a}$ by $1000 \mathrm{~L} \mathrm{~m}^{-3}$ results in an ambient ROS concentration in nmol $\mathrm{H}_{2} \mathrm{O}_{2}$ equivalents $\mathrm{m}^{-3}$.

\subsection{Evaluation of gas phase removal and $\operatorname{ROS}_{p}$ calculation by difference}

Several compounds were assessed as dry scrubbers or as annular denuder coatings for use in $\mathrm{ROS}_{\mathrm{g}}$ removal to improve determination of $\mathrm{ROS}_{\mathrm{p}}$. A glass annular denuder (URG) coated with a slurry of $\mathrm{MnO}_{2}$ and a diffusion dryer filled with Carulite (a dry $\mathrm{MnO}_{2}$ compound) (Carus Corporation, Peru, IL, USA) were evaluated for their ability to remove $\operatorname{ROS}_{\mathrm{g}}$. $\mathrm{MnO}_{2}$ was of primary interest since this has been an ROS removal compound used in previous studies (Hwang and Dasgupta, 1986; Stobbe et al., 1999). Ti(IV) oxalate was also used in an annular denuder coating, given its use in scrubbing

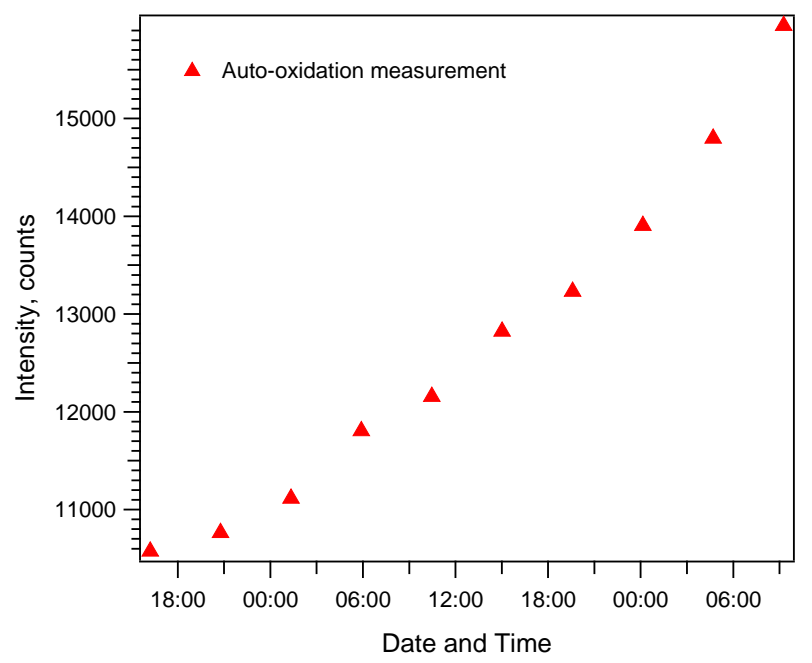

Fig. 7. Auto-oxidation (pure water blank) measurements of DCFH over time, demonstrating the drift of the DCFH working solution during regular operation of the online instrument.

hydrogen peroxide (Possanzini et al., 1988; Possanzini and Di Palo, 1995).

Denuder efficiency tests were done by consecutive denuder-on versus denuder-bypass ROS measurements with the automated mist chamber system by placing the Teflon filter upstream of the complete system, and the denuder in the position formerly occupied by the filter controlled by the air selection valve. The annular denuder coated with a $\mathrm{MnO}_{2}$ slurry removed an average of $9 \%$ of the ambient $\mathrm{ROS}_{\mathrm{g}}$, with a maximum removal efficiency of $57 \%$ (standard deviation of removal efficiency was $21 \%(n=111))$. Dry $\mathrm{MnO}_{2}$ packed into the diffusion dryer removed an average of $18 \%$, with a maximum of $39 \%$ and a standard deviation of $11 \%(n=113)$. Ti(IV) oxalate denuders were evaluated for a briefer period of time, with an average removal efficiency of $12 \%$ and a standard deviation of $33 \%(n=24)$.

Tests were also performed to determine if there were $\mathrm{ROS}_{\mathrm{g}}$ interferences from ozone. Measurements from sampling laboratory-generated ozone at concentrations between 60 and $180 \mathrm{ppb}$ showed little response, as expected given its low solubility ( $K_{\mathrm{H}}$ of $0.011 \mathrm{M} \mathrm{atm}^{-1}$ ) (Kosak-Channing and Helz, 1983).

The low removal efficiency and high variability suggested that these denuders would not be effective in removing $\mathrm{ROS}_{\mathrm{g}}$ consistently enough to include in a system that depended on reliable gas removal for artifact-free measurements. This conclusion led to the regular use of the difference method for determining $\mathrm{ROS}_{\mathrm{p}}$ from ROS $\mathrm{R}_{\mathrm{t}}$ and $\mathrm{ROS}_{\mathrm{g}}$, measured in an alternating fashion. $\mathrm{ROS}_{\mathrm{p}}$ in nmol $\mathrm{H}_{2} \mathrm{O}_{2}$ equivalents $\mathrm{m}^{-3}$ was determined by

$\operatorname{ROS}_{p, i}=\frac{\left[\operatorname{ROS}_{t, i}-\operatorname{ROS}_{g, i-1}\right]+\left[\operatorname{ROS}_{g, i}-\operatorname{ROS}_{g, i+1}\right]}{2}$,

where $i$ represents the number in the series of consecutive ROS measurements. 


\subsection{Precision and limits of detection}

Precision was determined by the standard deviation of a repeated standard in a calibration setting and the periodic measurement of standards during routine field operation of the instrument. The analytical precision based on repeated calibration standards was $6.2 \%, n=30(1.26 \mathrm{nM}$ liquid concentration, or under normal operating parameters, $0.025 \mathrm{nmol} \mathrm{H}_{2} \mathrm{O}_{2}$ equivalents $\mathrm{m}^{-3}$ ). Precision of the fielddeployed instrument, based on periodic measurements of standards during routine operation, was $7.1 \%(n=10)$.

The limit of detection for measuring ROS considering just the analytical portion of the method was determined by three times the standard deviation of the blank measurements made in succession (DCFH working solution and dI). The resulting liquid concentration limit of detection was $0.28 \mathrm{nM} \mathrm{H}_{2} \mathrm{O}_{2}$ equivalents, or $0.029 \mathrm{nmol} \mathrm{H}_{2} \mathrm{O}_{2}$ equivalents $\mathrm{m}^{-3}$ for the normal operational values of the mist chamber, in which the final liquid volume is $9.7 \mathrm{~mL}$, airflow rate $20 \mathrm{~L} \mathrm{~min}^{-1}$ and the sample collection time $5 \mathrm{~min}$. For the field-deployed instrument, ROS measurement limit of detection (LOD) was similar for consecutive blanks.

The method LOD for determining $\operatorname{ROS}_{\mathrm{p}}$ is substantially higher, however, since it involves a difference between two large values of relatively close magnitude. During the field measurements described below, frequent negative $\mathrm{ROS}_{\mathrm{p}}$ values resulted from the difference calculation. An alternate and conservative LOD was use based on the variability in the negative $\mathrm{ROS}_{\mathrm{p}}$ values. For example, once $\mathrm{ROS}_{\mathrm{p}}$ was determined for a specific study period (e.g., a specific site) and after basic quality control removed erroneous measurements of erratic highs or lows, the LOD for the particle measurements was estimated from one standard deviation of all negative values calculated from the difference method. The calculated LOD by this method varied between 0.07 and $0.19 \mathrm{nmol} \mathrm{H}_{2} \mathrm{O}_{2}$ equivalents $\mathrm{m}^{-3}$, with an average value of $0.15 \mathrm{nmol} \mathrm{H}_{2} \mathrm{O}_{2}$ equivalents $\mathrm{m}^{-3}$. The high LOD associated with this difference method emphasizes the importance of reducing or eliminating the gas signal from the particle measurement. Future progress is needed in this area to improve the $\mathrm{ROS}_{\mathrm{p}}$ method used in this work.

\section{Results and discussion}

\subsection{Field deployment}

The ROS mist chamber was evaluated for ambient sampling by deployment at a number of sites during various seasons. Sites included the Southeastern Aerosol Research and Characterization (SEARCH) network Jefferson Street site (JST) from 7 February to 2 March 2012, and 8 May to 31 May 2012. Located in central urban Atlanta, $\mathrm{GA}$, the site is considered representative of urban Atlanta (Hansen et al., 2006). Measurements were made at Yorkville
Table 2. Comparison of average and span of online $\mathrm{ROS}_{\mathrm{p}}$ measurements during summer study period.

\begin{tabular}{lllll}
\hline & $\begin{array}{l}\mathrm{ROS}_{\mathrm{p}} \text { Mean } \\
\left(\mathrm{nmol} \mathrm{H}_{2} \mathrm{O}_{2}\right. \\
\left.\text { equivalents } \mathrm{m}^{-3}\right)\end{array}$ & $\begin{array}{l}\text { Total No. of } \\
\text { Measurements } \\
\text { below LOD }\end{array}$ & Range & $\begin{array}{l}\text { Standard } \\
\text { Deviation }\end{array}$ \\
\hline $\begin{array}{l}\text { May 2012 } \\
(\text { JST })(N=998)\end{array}$ & $0.26 \pm 0.013$ & 725 & $0.04-2.74$ & 0.33 \\
$\begin{array}{l}\text { June 2012 } \\
\text { (YRK) }(N=439)\end{array}$ & $0.14 \pm 0.0091$ & 351 & $0.07-1.95$ & 0.19 \\
$\begin{array}{l}\text { July 2012 } \\
(\text { GT })(N=512)\end{array}$ & $0.24 \pm 0.010$ & 128 & $0.15-2.97$ & 0.29 \\
\hline
\end{tabular}

(YRK), the SEARCH rural pair to JST located approximately $80 \mathrm{~km}$ northwest of Atlanta, 8 June to 29 June 2012. Finally, measurements were made from the rooftop monitoring site at Georgia Tech (GT) (midtown Atlanta), 3 July to 31 July 2012, a site more impacted by highway traffic emissions than the JST site.

An example of the type of raw data produced by the instrument is shown in Fig. 8. The time series of the fluorescent intensity at $530 \mathrm{~nm}$ shows a series of peaks starting from a baseline of roughly 6000 counts. Adjustments were made on a weekly basis to maintain the baseline intensity at this level as a surrogate for controlling LED output intensity and to create consistent excitation in the samples. Peak heights are the response to measurements when the DCFH working solution is mixed with either a dI "blank", a standard, or a mist chamber sample of ROS $\mathrm{t}_{\mathrm{t}}$ or ROS $\mathrm{g}$. ROS measurements and calibration standards are corrected by subtracting an estimated "blank" determined from a linear interpolation between successive auto-oxidation measurements. In this example, a set of 8 ROS measurements were made by alternating between $\mathrm{ROS}_{\mathrm{t}}$ and ROS $\mathrm{g}$ between blanks or standards. Standards are less frequently analyzed than blanks.

During May (JST) and June (YRK), the ROS instrument was operated using a 5 min sampling period, but increased to $30 \mathrm{~min}$ for later portions of the GT July study. Figure 9 shows the time series of $\operatorname{ROS}_{\mathrm{p}}$ measured at the Georgia Tech site. Table 2 provides a statistical summary of $\operatorname{ROS}_{p}$ concentrations from each site. The ambient results are discussed following a comparison between the online system and filter measurements.

\subsection{Comparison with filter concentrations}

A short $\operatorname{ROS}_{\mathrm{p}}$-filter study was conducted in order to compare online $\operatorname{ROS}_{\mathrm{p}}$ concentrations to the more traditional methods used to date. This comparison study was conducted in July 2012 while the instrument was deployed at the Georgia Tech site. Over a period of 16 weekdays, $1 \mu \mathrm{m}$ polycarbonate filters (Nuclepore, Whatman) were loaded with PM at an average flow rate of $45 \mathrm{~L} \mathrm{~min}^{-1}$. Measurements were made of total suspended particulate matter; no size selector was used so that the filter flow rate could be maximized. To minimize sampling artifacts, sampling times were kept short, typically 


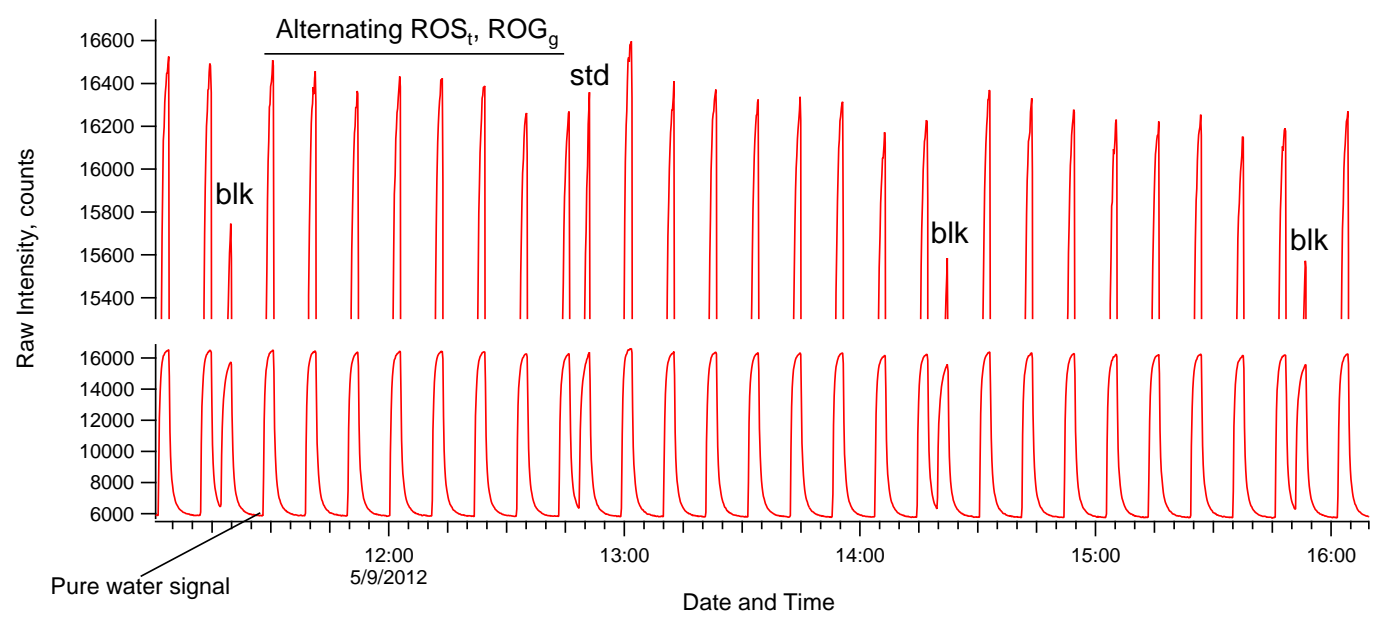

Fig. 8. Time series of raw spectrometer data for ambient ROS measurements showing responses for pure water, deionized water + DCFH/HRP (blk), online measurements of total and gas ROS, and $\mathrm{H}_{2} \mathrm{O}_{2}$ standards (std).

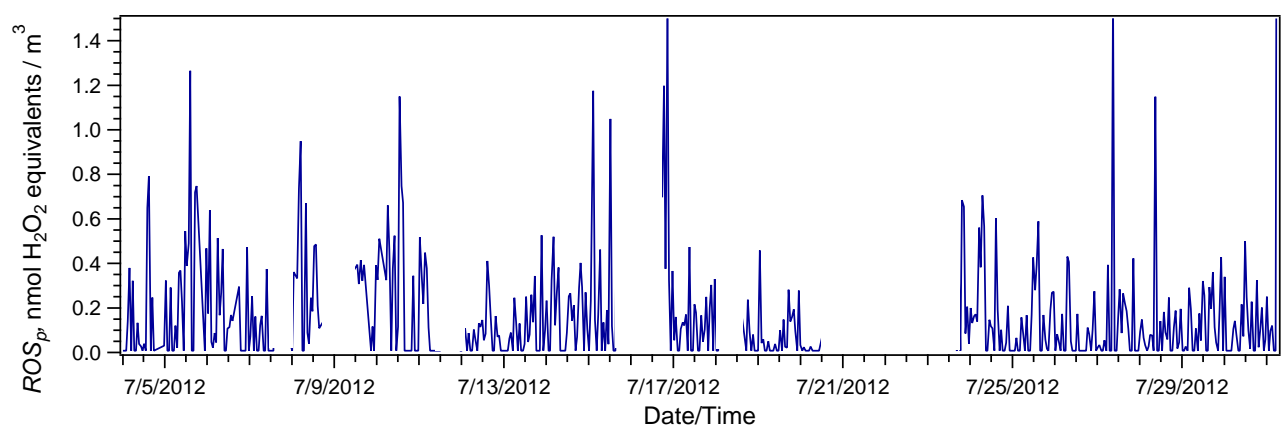

Fig. 9. Time series plot of $\operatorname{ROS}_{\mathrm{p}}$ at the Georgia Tech sites. $\operatorname{ROS}_{\mathrm{p}}$ below estimated limit of detection is plotted as $0.5 \cdot(\mathrm{LOD})$.

$3 \mathrm{~h}$. Following sampling, filters were immediately extracted into $30 \mathrm{~mL}$ of the same batch of DCFH working solution being used in the co-located online instrument, mechanically shaken using a wrist-action shaker (mechanical wrist action shaker, Model 70, Burrell Scientific, Pittsburgh, PA, USA) for $15 \mathrm{~min}$ and analyzed using an identical setup to the online system. This procedure deviated from other studies' filter measurements (Hung and Wang, 2001) in two ways: one, the same volume of DCFH was used for each filter, and, two, filters were shaken rather than sonicated to extract the particles into solution. Filter blanks and water blanks were also measured and standards were checked routinely.

Since the majority of the online measurements were comprised of values at or below the LOD, only average comparisons are made between the filter and online $\operatorname{ROS}_{\mathrm{p}}$. No filter measurement was below the filter LOD $\left(0.016 \mathrm{nmol} \mathrm{H}_{2} \mathrm{O}_{2}\right.$ equivalents $\mathrm{m}^{-3}$ ). In cases where measurements were below the LOD, 1/2 LOD was used in the statistical calculations. Results from the filter comparison are detailed in Table 3. The filter measurements tend to agree with the online results, despite the fact the filters were TSP and the online method sampled $\mathrm{PM}_{2.5}$. The average filter
Table 3. Comparison of online and offline $\operatorname{ROS}_{\mathrm{p}}$ measurements, 12-27 July 2012.

\begin{tabular}{llll}
\hline & $\begin{array}{l}\mathrm{ROS}_{\mathrm{p}} \mathrm{Mean} \\
\left(\mathrm{nmol} \mathrm{H}_{2} \mathrm{O}_{2}\right. \\
\left.\text { equivalents } \mathrm{m}^{-3}\right)\end{array}$ & Range & $\begin{array}{l}\text { Standard } \\
\text { Deviation }\end{array}$ \\
\hline Online (mist chamber) & $0.16 \pm 0.010$ & $0.01-0.70$ & 0.17 \\
Offline (filters) $(N=19)$ & $0.15 \pm 0.019$ & $0.05-0.34$ & 0.079
\end{tabular}

$\operatorname{ROS}_{\mathrm{p}}$ was $0.15 \mathrm{nmol} \mathrm{H}_{2} \mathrm{O}_{2}$ equivalents $\mathrm{m}^{-3}$ compared to $0.16 \mathrm{nmol} \mathrm{m}^{-3}$ for the online system. The online data are largely driven by adjustments made for values below the LOD. This agreement suggests that the online measurement methods employed during this study are as effective as making careful yet rapid filter (e.g., highly labor-intensive) measurements of ambient ROS. 
Table 4. Summary of $\operatorname{ROS}_{\mathrm{p}}$ studies.

\begin{tabular}{llll}
\hline Location & Dates & $\begin{array}{l}\text { Concentration } \\
\left(\mathrm{nmol} \mathrm{m}^{-3}\right)\end{array}$ & Reference \\
\hline Flushing, NY & Jan-Feb 2004 & $0.87 \pm 0.18$ & Venkatachari et al. (2007) \\
Singapore (roadway) & Dec 2005 & $15.10 \pm 0.10$ & See et al. (2007) \\
Singapore (ambient) & Dec 2005 & $5.71 \pm 2.30$ & See et al. (2007) \\
Taipei (Taiwan) & Jul-Dec 2000 & $0.54 \pm 0.40$ & Hung and Wang (2001) \\
Rubidoux, CA & Jul 2003 & $5.90 \pm 1.70$ & Venkatachari et al. (2005) \\
Rochester, NY & Aug 2009 & $8.30 \pm 2.19$ & Wang et al. (2011) \\
Atlanta, GA (online) & May, Jul 2012 & $0.25 \pm 0.01$ & This study \\
Atlanta, GA (filters) & Jul 2012 & $0.15 \pm 0.019$ & This study \\
\hline
\end{tabular}

\section{Discussion of online field results}

Both urban sites (JST and GT) showed significantly higher $\mathrm{ROS}_{\mathrm{p}}$ concentrations when compared with the rural site (YRK) $(p<0.001$ and $p<0.05$ respectively). The JST and GT mean $\operatorname{ROS}_{\mathrm{p}}$ concentrations were also different $(p<0.001)$ at 0.26 and 0.24 nmol $\mathrm{H}_{2} \mathrm{O}_{2}$ equivalents $\mathrm{m}^{-3}$, respectively, whereas YRK was roughly half that at $0.14 \mathrm{nmol} \mathrm{H}_{2} \mathrm{O}_{2}$ equivalents $\mathrm{m}^{-3}$. These numbers are uncertain since much of the data were below the LOD of $0.15 \mathrm{nmol} \mathrm{m}^{-3}$, but the urban sites had fewer values below LOD, consistent with generally higher $\operatorname{ROS}_{\mathrm{p}}$ values.

The GT location is much closer to a congested 16-lane highway that runs through the middle of the city. Online measurements of elemental carbon (EC), a tracer for primary aerosol, show a greater influence of roadway emissions at GT. For example, GT / JST EC ratio was 1.36 for July 2012. This comparison, though, is somewhat ambiguous since the $\operatorname{ROS}_{\mathrm{p}}$ measurements made at the two sites were at different times (JST in May 2012, GT in July 2012), but still no large difference is observed for a site expected to be more impacted by highway emissions. The lower concentrations at the rural site suggest urban emission may be related to $\operatorname{ROS}_{\mathrm{p}}$.

These offline and online measurements of $\operatorname{ROS}_{\mathrm{p}}$ are generally lower than what has been reported by other investigators, as summarized previously (Wang et al., 2011) and shown in Table 4. Filter-based studies have reported $\mathrm{ROS}_{\mathrm{p}}$ concentrations in the range of 0.54 to $15.1 \mathrm{nmol} \mathrm{H}_{2} \mathrm{O}_{2}$ equivalents $\mathrm{m}^{-3}$, about an order of magnitude above levels measured in this study. The few online studies conducted over much shorter time periods ( 1 week) report a mean $\mathrm{ROS}_{\mathrm{p}}$ concentration of $8.30 \pm 2.19 \mathrm{nmol} \mathrm{m}^{-3}$ (Wang et al., 2011). The highest concentrations are found in studies conducted next to roadways, possibly suggesting that extremely fresh emissions from these locations can lead to higher measured concentrations. It is not clear why the concentrations in Atlanta and vicinity are significantly lower. This could be due to different emission characteristics, linked to different measurement methods, or due to some of the substantial challenges associated with using this chemical probe.

\section{Conclusions}

An automated flow system and online instrument was developed for analysis of ROS using a mist chamber collection system coupled to an analytical system employing DCFH as a fluorescent probe. The system was operated using a set of operational parameters optimized based on extensive laboratory experiments. The analytical system LOD was $0.28 \mathrm{nM}$. This detector was coupled to a mist chamber for collecting and concentrating ROS components in water. $\mathrm{PM}_{2.5}$ ROS $\left(\operatorname{ROS}_{\mathrm{p}}\right)$ was determined by the difference between total gas plus particle $\left(\mathrm{ROS}_{\mathrm{t}}\right)$ and filtered air (i.e., gas-phase ROS, $\mathrm{ROS}_{\mathrm{g}}$ ). This method was chosen since experiments with various denuders showed low and variable effectiveness for removing ROS $_{\mathrm{g}}$. Higher LODs are associated with this method versus potential direct online methods due to high $\mathrm{ROS}_{\mathrm{g}}$ levels relative to $\operatorname{ROS}_{\mathrm{p}}$. For the three months of measurements reported in this study, the percentage of $\mathrm{ROS}_{\mathrm{g}}$ to total $\mathrm{ROS}_{\mathrm{g}} / \mathrm{ROS}_{\mathrm{t}}$ was $96 \pm 124 \%$ (one standard deviation). Online measurements were above the detection limit of nominal $0.15 \mathrm{nmol} \mathrm{H}_{2} \mathrm{O}_{2}$ equivalents $\mathrm{m}^{-3}$ approximately $25 \%$ of the time. $\mathrm{ROS}_{\mathrm{g}}$ artifacts can be reasonably expected to dominate other liquid-based systems. During the field deployment of the instrument, concentrations of $\operatorname{ROS}_{\mathrm{p}}$ were higher in urban areas relative to a rural site, averaging $0.25 \mathrm{nmol} \mathrm{H}_{2} \mathrm{O}_{2}$ equivalents $\mathrm{m}^{-3}$ for urban Atlanta in May and July, versus $0.14 \mathrm{nmol} \mathrm{H}_{2} \mathrm{O}_{2}$ equivalents $\mathrm{m}^{-3}$ at the rural Yorkville site during June. These online results were consistent with a series of filter samples using the same ROS analytical system designed for the online method. The $\mathrm{ROS}_{\mathrm{p}}$ reported in this study is significantly below what has been reported by other investigators, with ranges between 0.54 and $15.1 \mathrm{nmol} \mathrm{H}_{2} \mathrm{O}_{2}$ equivalents $\mathrm{m}^{-3}$. Application of the DCFH probe to measurement of ambient particle ROS is challenging due to a number of factors, including auto-oxidation of the working solution over a short period of time as well as photosensitivity and potential for large interferences from $\mathrm{ROS}_{\mathrm{g}}$.

Acknowledgements. This research was made possible through USEPA grant R834799. The contents of this paper are solely the responsibility of the grantee and do not necessarily represent the official views of the USEPA. Further, USEPA does not endorse the purchase of any commercial products or services mentioned in the publication. This research was also made possible in part by collocating field deployments with sites operated by Atmospheric Research and Analysis (ARA) as part of the Southeastern Aerosol Research and Characterization (SEARCH) network of monitoring stations, which are funded in part by the Electric Power Research Institute (EPRI) and the Southern Company. This work does not necessarily represent the views of any of the above parties, nor do they endorse any of the commercial products mentioned within this text.

Edited by: P. Herckes 


\section{References}

Anderson, C. H., Dibb, J. E., Griffin, R. J., Hagler, G. S. W., and Bergin, M. H.: Atmospheric water-soluble organic carbon measurements at Summit, Greenland, Atmos. Environ., 42, 56125621, doi:10.1016/j.atmosenv.2008.03.006, 2008.

Antonini, J. M., Clarke, R. W., Murthy, G. G. K., Sreekanthan, P., Jenkins, N., Eagar, T. W., and Brain, J. D.: Freshly generated stainless steel welding fume induces greater lung inflammation in rats as compared to aged fume, Toxicol. Lett., 98, 77-86, 1998.

Barrett, W. C., DeGnore, J. P., Keng, Y.-F., Zhang, Z.-Y., Yim, M. B., and Chock, P. B.: Roles of Superoxide Radical Anion in Signal Transduction Mediated by Reversible Regulation of Proteintyrosine Phosphatase 1B, J. Biol. Chem., 274, 34543-34546, 1999.

Black, M. J. and Brandt, R. B.: Spectrofluorometric Analysis of Hydrogen Peroxide, Anal. Biochem., 58, 246-254, 1974.

Cathcart, R., Schwiers, E., and Ames, B. N.: Detection of Picolmole Levels of Hydroperoxides Using a Fluorescent Dichlorofluorescein Assay, Anal. Biochem., 134, 111-116, 1983.

Cofer III, W. R., Collins, V. G., and Talbot, R. W.: Improved Aqueous Scrubber for Collection of Soluble Atmospheric Trace Gases, Environ. Sci. Technol., 19, 557-560, 1985.

Cofer III, W. R., Edahl, J., and Robert A.: A New Technique For Collection, Concentration and Determination of Gaseous Tropospheric Formaldehyde, Atmos. Environ., 20, 979-984, 1986.

Cohn, C. A., Simon, S. R., and Schoonen, M. A. A.: Comparison of fluorescence-based techniques for the quantification of particleinduced hydroxyl radicals, Particle and fibre toxicology, 5, 2, doi:10.1186/1743-8977-5-2, 2008.

Hansen, A., Edgerton, E., Hartsell, B., Jansen, J., Burge, H., Koutrakis, P., Rogers, C., Suh, H., Chow, J., Zielinska, B., McMurry, P., Mulholland, J., Russell, A., and Rasmussen, R.: Air Quality Measurements for the Aerosol Research and Inhalation Epidemiology Study, J. Air Waste Manage. As., 56, 1445-1458, 2006.

Hung, H.-F. and Wang, C.-S.: Experimental determination of reactive oxygen species in Taipei aerosols, J. Aerosol Sci., 32, 12011211, 2001.

Hwang, H. and Dasgupta, P. K.: Fluorometric flow injection determination of aqueous peroxides at nanomolar level using membrane reactors, Anal. Chem., 58, 1521-1524, doi:10.1021/ac00298a055, 1986.

Kao, M.-C. and Wang, C.-S.: Reactive Oxygen Species in Incense Smoke, Aerosol Air Quality Res., 2, 61-69, 2002.

Klippel, T., Fischer, H., Bozem, H., Lawrence, M. G., Butler, T., Jöckel, P., Tost, H., Martinez, M., Harder, H., Regelin, E., Sander, R., Schiller, C. L., Stickler, A., and Lelieveld, J.: Distribution of hydrogen peroxide and formaldehyde over Central Europe during the HOOVER project, Atmos. Chem. Phys., 11, 4391-4410, doi:10.5194/acp-11-4391-2011, 2011.

Kosak-Channing, L. F. and Helz, G. R.: Solubility of Ozone in Aqueous Solutions of 0-0.6 M Ionic Strength at 5-30 C, Environ. Sci. Technol., 17, 145-149, 1983.

LeBel, C. P., Ischiropolous, H., and Bondy, S. C.: Evaluation of the Probe $2^{\prime}, 7^{\prime}$-Dichiorofluorescin as an Indicator of Reactive Oxygen Species Formation and Oxidative Stress, Chem. Res. Toxicol., 5, 227-231, 1992.

Lee, J. H., Chen, Y., and Tang, I. N.: Heterogeneous Loss of Gaseous $\mathrm{H}_{2} \mathrm{O} 2$ in an Atmospheric Air Sampling System, Env- iron. Sci. Technol., 25, 339-342, 1991

Liu, H. H., Wu, Y. C., and Chen, H. L.: Production of ozone and reactive oxygen species after welding, Archives of environmental contamination and toxicology, 53, 513-518, doi:10.1007/s00244-007-0030-1, 2007.

Morgan, T. E., Davis, D. A., Iwata, N., Tanner, J. A., Snyder, D., Ning, Z., Kam, W., Hsu, Y.-T., Winkler, J. W., Chen, J.-C., Petasis, N. A., Baudry, M., Sioutas, C., and Finch, C. E.: Glutamatergic Neurons in Rodent Models Respond to Nanoscale Particulate Urban Air Pollutants In Vivo and In Vitro, Environ. Health Persp., 119, 1003-1009, 2001.

Oberdörster, E.: Manufactured Nanomaterials (Fullerenes, C60) Induce Oxidative Stress in the Brain of Juvenile Largemouth Bass, Environ. Health Persp., 112, 1058-1062, doi:10.1289/ehp.7021, 2004.

Orsini, D. A., Ma, Y., Sullivan, A., Sierau, B., Baumann, K., and Weber, R. J.: Refinements to the particle-into-liquid sampler (PILS) for ground and airborne measurements of water soluble aerosol composition, Atmos. Environ., 37, 1243-1259, doi:10.1016/s1352-2310(02)01015-4, 2003.

Pope, C. A., Thun, M. J., Namboodiri, M. M., Dockery, D. W., Evans, J. S., Speizer, F. E., and Heath, C. W.: Particulate air pollution as a predictor of mortality in a prospective study of US adults, Am. J. Resp. Crit. Care, 151, 669-674, 1995.

Possanzini, M. and Di Palo, V.: Improved titanium method for determination of atmospheric $\mathrm{H}_{2} \mathrm{O}_{2}$, Anal. Chim. Acta, 315, 225-230, 1995.

Possanzini, M., Di Palo, V., and Liberti, A.: Annular denuder method for determination of $\mathrm{H}_{2} \mathrm{O}_{2}$ in the ambient atmosphere, Sci. Total Environ., 77, 203-214, 1988.

Reeves, C. E. and Penkett, S. A.: Measurements of Peroxides and What They Tell Us, Chem. Rev., 103, 5199-5218, 2003.

Rothe, G. and Valet, G.: Flow Cytometric Analysis of Respiratory Burst Activity in Phagocytes with Hydroethidine and $2^{\prime}, 7^{\prime}$ Dichlorofluorescin, J. Leukocyte Biol., 47, 440-448, 1990.

See, S. W., Wang, Y. H., and Balasubramanian, R.: Contrasting reactive oxygen species and transition metal concentrations in combustion aerosols, Environ. Res., 103, 317-324, 2007.

Spaulding, R. S., Talbot, R. W., and Charles, M. J.: Optimization of a Mist Chamber (Cofer Scrubber) for Sampling Water-Soluble Organics in Air, Environ. Sci. Technol., 36, 1798-1808, 2002.

Squadrito, G. L., Cueto, R., Dellinger, B., and Pryor, W. A.: Quinoid Redox Cycling as a Mechanism for Sustained Free Radical Generation by Inhaled Airborne Particulate Matter, Free Radical Biol. Med., 31, 1132-1138, 2001.

Stobbe, E. R., de Boer, B. A., and Geus, J. W.: The reduction and oxidation behaviour of manganese dioxides, Catal. Today, 47, 161$167,1999$.

Sugamura, K. and Keaney, J., and John F.: Reactive oxygen species in cardivascular disease, Free Radical Biol. Med., 51, 978-992, 2011.

Venkatachari, P. and Hopke, P. K.: Development and Laboratory Testing of an Automated Monitor for the Measurement of Atmospheric Particle-Bound Reactive Oxygen Species (ROS), Aerosol Sci. Technol., 42, 629-635, doi:10.1080/02786820802227345, 2008.

Venkatachari, P., Hopke, P. K., Grover, B. D., and Eatough, D. J.: Measurement of Particle-Bound Reactive Oxygen Species in Rubidoux Aerosols, J. Atmos. Chem., 50, 49-58, 2005. 
Venkatachari, P., Hopke, P. K., Brune, W. H., Ren, X., Lesher, R., Mao, J., and Mitchell, M.: Characterization of Wintertime Reactive Oxygen Species Concentrations in Flushing, New York, Aerosol Sci. Technol., 41, 97-111, doi:10.1080/02786820601116004, 2007.

Votyakova, T. V. and Reynolds, I. J.: Detection of hydrogen peroxide with Amplex Red: interference by NADH and reduced glutathione auto-oxidation, Arch. Biochem. Biophys., 431, 138144, doi:10.1016/j.abb.2004.07.025, 2004.

Wang, Y., Arellanes, C., Curtis, D. B., and Paulson, S. E.: Probing the Source of Hydrogen Peroxide Associated with Coarse Mode Aerosol Particles in Southern California, Environ. Sci. Technol., 44, 4070-4075, 2010.

Wang, Y., Hopke, P. K., Sun, L., Chalupa, D. C., and Utell, M. J.: Laboratory and field testing of an automated atmospheric particle-bound reactive oxygen species sampling-analysis system, J. Toxicol., 2011, 9 pp., doi:10.1155/2011/419476, 2011.
Xia, T., Kovochich, M., Brant, J., Hotze, M., Sempf, J., Oberley, T., Sioutas, C., Yeh, J. I., Wiesner, M. R., and Nel, A.: Comparison of the Abilities of Ambient and Manufactured Nanoparticles To Induce Cellular Toxicity According to an Oxidative Stress Paradigm, Nano Letters, 6, 1794-1807, 2006.

Zhou, M., Diwu, Z., Panchuk-Voloshina, N., and Haugland, R. P.: A Stable Nonfluorescent Derivative of Resorufin for the Fluorometric Determination of Trace Hydrogen Peroxide: Applications in Detecting the Activity of Phagocyte NADPH Oxidase and Other Oxidases, Anal. Biochem., 253, 162-168, 1997. 